\title{
The Emerging Role of Pituitary Tumor Transforming Gene in Tumorigenesis
}

\author{
Jacob Tfelt-Hansen, MD; Deepthi Kanuparthi, MSc; and Naibedya Chattopadhyay, PhD
}

\begin{abstract}
Pituitary tumor transforming gene (PTTG) is a newly discovered oncogene, and serves as a marker of malignancy grades in several forms of cancer, particularly endocrine malignancies such as pituitary adenomas. PTTG appears also to have a role in the genesis of some types of cancer. Also known as a human form of securin, PTTG is an anaphase inhibitor that prevents premature chromosome separation through inhibition of separase activity; hence, its degradation is required to start anaphase. Through this important function, PTTG participates in several key cellular events such as mitosis, cell cycle progression, DNA repair and apoptosis. The physiological importance of PTTG is indicated by the study of PTTG-null mice that have cell growth abnormalities in testis and pancreatic beta cells. Overexpression of PTTG has been observed in thyroid and colon cancers. In addition, $90 \%$ of pituitary adenomas overexpress PTTG, qualifying it as the best available marker for this disease. Although the exact mechanism is unknown, PTTG participates in the pathogenesis of various tumors, including pituitary tumors, by inducing aneuploidy and upregulating FGF-2, a potent mitogenic and angiogenic factor.Various growth factors, nuclear factors and hormones regulate PTTG expression in different tumor cells, which could be important to understand in order to obtain insight into the tumorigenic and tumor progression process. Here, we review the current knowledge of the biological and pathophysiological roles of PTTG.
\end{abstract}

Keywords: Aneuploidy; Angiogenesis; Cell cycle; Pituitary adenoma

$\mathrm{P}$ tumor-specific oncogene that was discovered a decade ago. It is expressed in pituitary tumors but not in normal pituitary cells and is currently the best available marker of pituitary adenomas. Available data increasingly implicate PTTG overexpression with malignancy grades in thyroid, colon and astroglial cancers. Furthermore, there is a rising body of evidence suggesting that PTTG, and its binding protein, participate in the genesis of some cancers.

Equal separation of sister chromatids is an essential step for chromosome segregation and is fundamental to the inheritance of genetic material. In somatic cells, sister chromatid separation occurs once in the cell cycle during a brief mitotic step called anaphase. Anaphase is triggered by a protease called separase, which is normally kept inactive by an associated inhibitor called securin. ${ }^{1-3}$ When PTTG is ubiquitinated by the anaphase-promoting complex or cyclosome (APC/C), ${ }^{4-6}$ it is destroyed by the proteasome,

Reprint Requests: Jacob Tfelt-Hansen, MD, Laboratory of Molecular Cardiology, Department of Cardiology, Copenhagen University Hospital Rigshospitalet, 20 Juliane Maries Vej, Section 9312, DK 2100 Copenhagen O, Denmark, E-mail: tfelt@dadlnet.dk leading to separase activation, Scc1 cleavage, loss of chromosome cohesion and onset of anaphase. ${ }^{2,3}$ Loss of chromosome cohesion allows segregation of sister chromatids toward opposite spindle poles during anaphase. Under aberrant conditions, when sister chromatids are pulled to the same pole, aneuploid daughter cells are produced.

Aneuploidy, frequently noted in human cancers, is characterized by alterations in the number of chromosomes due to defects in a cell cycle surveillance mechanism, called the spindle checkpoint, resulting in chromosomal instability. PTTG, also known as human securin, is a mitotic checkpoint gene involved at the metaphase-anaphase interface. PTTG is abundantly expressed in several neoplasms. Its overexpression in human normal and cancer cells induces aneuploidy with micronuclei and multiple nuclei. PTTG also exhibits transforming activity, and its overexpression may lead to tumorigenesis. In this article we review the current developments in understanding the role of PTTG in tumorigenesis and the underlying biological mechanisms.

Grant Support: Grant Support: Danish Arrhythmia Research Center, Statens Sundheds Videnskablige Forskningsråd and the Danish Heart Association to J.T.H and a National Institutes of Health grant (AR-02215) to N.C.

Revision 2 Received: March 27, 2006

Accepted: March 27, 2006 


\section{Cloning, Characterization and Function of PTTG Indicate Its Tumorigenic Role}

PTTG was first identified by differential display polymerase chain reaction (PCR) between rat pituitary tumor cells (GH4) and normal pituitary tissue. It was observed that PTTG mRNA is exclusively expressed in pituitary tumor but not in normal pituitary tissue. ${ }^{7}$ Full-length PTTG mRNA, cloned from the GH4 cell line, is 974 base pairs (bp) with an open reading frame for 199 amino acids. The human PTTG family comprises at least three homologous proteins, of which the structure and function of only PTTG-1 have been studied in detail. ${ }^{8,9}$ The gene for human PTTG is located on chromosome 5 and encodes a protein of 202 amino acids $(22 \mathrm{kDa})$ with no significant homology to other known proteins. ${ }^{10}$ PTTG is a multidomain protein consisting of a transactivation domain, a domain required for ubiquitin-mediated proteolysis and a DNA-binding domain (mapped from amino acids 60-118). ${ }^{11}$ At the end of the metaphase of cell division, PTTG is rapidly degraded by an anaphase promoting complex that recognizes a conserved motif within its $\mathrm{N}$-terminus called the destruction box, releasing the inhibition of separin, which in turn leads to the degradation of separin proteins. ${ }^{1}$ Eventually PTTG is degraded by the ubiquitin pathway to ensure equal sister chromatid separation. ${ }^{12}$

Like any other oncogene, PTTG has normal physiological functions that were revealed by deleting the PTTG gene in mice. These PTTG-deficient mice exhibit a variety of cell growth abnormalities, including testicular and splenic hypoplasia, thymic hyperplasia and, diabetes mellitus secondary to defective beta-cell proliferation. ${ }^{13}$ However, the tumorigenic potential of PTTG was demonstrated by its ability to transform NIH-3T3 fibroblasts following PTTG overexpression. This transformation resulted in morphological changes and anchorage-independent growth of PTTG transfectants in soft agar. ${ }^{8}$ Furthermore, when nude mice were injected with PTTG-expressing NIH-3T3 cells, they developed large tumors at the injection sites, suggesting that PTTG is capable of cellular transformation without the requirement of a complimentary oncogene and that it is tumorigenic in vivo. ${ }^{7}$ These observations implicated PTTG in the genesis and progression of cancer. PTTG has dual roles in tumorigenesis. First, through its action as a key regulator of cell division, overexpression of PTTG initiates genetic instability. Second, as a transactivator of growth factors, high PTTG expression induces fibroblast growth factor (FGF)-2, vascular endothelial growth factor (VEGF) and other proangiogenic genes. Thus, PTTG appears to be both an initiator and a promoter of tumorigenesis, and one whose expression has been correlated with tumor progression and metastatic potential across a plethora of tumor types as discussed below.

\section{PTTG and Pituitary Tumors}

Pituitary adenomas are neuroendocrine tumors that produce endocrine and metabolic alterations and are the most common benign intracranial neoplasms. The genesis of pituitary tumors is controversial and largely unclear. Several mechanisms, including intrinsic alterations in pituicytes, hypothalamic dysregulation and locally produced growth factors, seem to underlie tumorigenesis. X-chromosomal inactivation analysis revealed that the majority of pituitary adenomas, as with most tumors, derive from the clonal expansion of a single pituitary cell. This transforming event provides selective growth advantage to the mutant cell, resulting in secondary mutations and/or alterations in the growth factors favorable to clonal expansion and tumor progression. Because of their clonal composition, most cases of pituitary tumor display excessive secretion of any given pituitary hormone which results in endocrine diseases such as Cushing's syndrome for adrenocorticotropic hormone (ACTH), acromegaly for growth hormone, hyperprolactinemia for prolactin and thyrotoxicosis for thyroid-stimulating hormone (TSH).

Gross aneuploidy is reported in sporadic pituitary adenomas at a prevalence of approximately $50 \%$. Genetic instability, or chromosomal alteration, is a classical mechanism of tumor formation, generating mutations in or overexpression of oncogenes and tumor suppressor genes. Sporadic and low-frequency mutations of oncogenes and tumor suppressor genes are observed in pituitary adenomas, ${ }^{14,15}$ but give no specific information about tumor development. Activating mutations of the oncogene, Gsp, in $40 \%$ of cases of growth hormone-producing adenomas has served as the best marker for pituitary adenoma, thus far. ${ }^{15}$ Cloning of PTTG was crucial in revealing that approximately $90 \%$ of pituitary adenomas overexpress this gene compared with normal pituitary tissue, which expresses very little PTTG. Several reports show that, although PTTG was upregulated in all histological subtypes, its expression is highest in $\mathrm{ACTH}$-secreting and nonfunctioning pituitary tumors. ${ }^{16-18}$ One study reported higher expression levels of PTTG, PTTG binding factor, and FGF-2 and its receptor FGFR1 mRNAs in pituitary adenomas as compared to normal tissue in 121 ex vivo pituitary tumors. In addition, FGFR1 expression was higher in hormone-secreting pituitary tumors that invade bone (the sphenoid bone) than in those that do not. ${ }^{19}$ These data suggest a causative association between the PTTG signaling pathway and FGF-2 in pituitary adenomas. In the clinical setting, where the measurement of conventional markers of aggressive tumors (e.g., expression of proliferating cell nuclear antigen (PCNA), Ki67 or bromodeoxyuridine labeling) have failed in cases of pituitary adenomas, ${ }^{20-23}$ PTTG and possibly FGF-2 and FGFR1 are currently the best available markers of pituitary tumors. The high sensitivity of PTTG as a marker of pituitary adenomas may be due to the fact that this protein participates in the transition of normal cells to benign tumors as in the case of pituitary adenomas, whereas PCNA and Ki67 overexpression is generally associated with the malignant transition of the tumors. In this regard, it would be interesting to determine whether the conventional treatments of pituitary tumors are accompanied by downregulation of PTTG expression, which could then be applied to monitor treatment efficacy. 
Abundant expression of PTTG in all adenoma subtypes indicates its importance in the genesis of pituitary tumors. This was shown elegantly in a mouse model where targeted overexpression of PTTG in pituitary tissue resulted in focal pituitary hyperplasia and adenoma formation. ${ }^{24}$ The cellular mechanism involves specific downregulation of a cyclin-dependent kinase inhibitor, p21, whose normal expression restrains tumor formation. In addition, mice bearing a single allele of the tumor suppressor gene, retinoblastoma $(\mathrm{Rb})$, develop pituitary tumors with almost complete penetrance. ${ }^{25,26}$ Deleting the PTTG gene in $\mathrm{Rb}^{+/}$mice has been shown to exert a protective effect on the high levels of penetrance observed in $\mathrm{Rb}^{+/-} \mathrm{PTTG}^{-/-}$mice. ${ }^{27}$ These studies suggest that the genesis of pituitary adenoma involves downregulation of $\mathrm{Rb}$ and $\mathrm{p} 21$ expression due to PTTG overexpression, since $\mathrm{Rb}$ stimulates $\mathrm{p} 21$ promoter activity.

PTTG is also known to promote tumor progression by stimulating expression and secretion of basic fibroblast growth factor (bFGF), ${ }^{8,18}$ a potent mitogenic and angiogenic factor. ${ }^{28,29}$ Overexpression of PTTG in transfected cells stimulates the expression of $\mathrm{bFGF}$, and a point mutation of the putative SH3-binding site within the C-terminal region of PTTG abrogates an increase in bFGF expression. ${ }^{30}$ In 2001, $\mathrm{Pei}^{30}$ demonstrated that PTTG transactivates bFGF transcription by interacting with PTTG-binding factor, which suggests that transcriptional activation is one of the important activities of PTTG. The PTTG transactivation domain has been mapped to a region between amino acids 119 and 164, which includes sequences that are acidic and proline-rich, characteristic of the transactivation domains of many other transcription factors. Transcriptional regulation of FGF2 expression by PTTG appears to require PTTG-binding factor to initiate PTTG's entry into the nucleus.

In the pituitary, members of the FGF family regulate pituitary growth and the transcription and secretion of prolactin. ${ }^{31-33}$ FGF-4 is also found in pituitary tumors, ${ }^{34}$ where its expression is higher than in normal cells and is detectable in large prolactinomas. In experimental prolactin-secreting tumors, FGF-4 correlates with proliferation. ${ }^{33}$ Finally, clinical studies ${ }^{35}$ reveal that PTTG-binding factor, FGF-2 and VEGF are elevated in pituitary tumors and mostly correlate with PTTG levels. These results corroborate experimental reports of the role of PTTG in angiogenesis and mitogenesis of pituitary adenomas. However, one group showed lack of correlation between PTTG overexpression and VEGF production in somatotropic tumors, suggesting a more complex cause and effect relationship between PTTG overexpression and the pathogenesis of pituitary adenoma. ${ }^{36}$ Despite this complex relationship, it is safe to suggest that paracrine activation of growth factor expression and secretion accounts for the induction of pituitary tumor formation by PTTG $^{18}$ and thus, qualifies it as a potential target for drug development for the treatment of pituitary adenoma. PTTG expression has also been correlated with progression of malignancy in other tissues.

\section{PTTG and Other Cancers}

\section{Thyroid cancer}

PTTG is expressed at high levels in a variety of human primary tumors in addition to pituitary adenomas and tumor cell lines (table 1). Thyroid cancer is the most common endocrine malignancy and, like pituitary tumors, is found more frequently in women. This form of cancer carries a fairly good prognosis, with a 10-year survival rate for differentiated thyroid carcinoma of approximately $90 \% .{ }^{37}$ The prognosis of patients with thyroid carcinoma is affected by factors related to the patient, the disease and the treatment. Disease- and patient-related positive factors are 1) a small and histologically well-differentiated primary tumor, 2) tumors limited to the thyroid gland, and 3) young age. ${ }^{38}$ Currently, there is no good molecular marker for the prognosis of the disease. A study investigating the expression of PTTG in thyroid neoplasias found PTTG mRNA to be upregulated in $50 \%$ (4/8) papillary carcinomas, $100 \%$ (2/2) minimally invasive follicular carcinomas, $77.8 \%$ (7/9) follicular adenomas, and $66.7 \%$ (10/15) thyroid hyperplasias. ${ }^{39}$ Another study also showed bFGF and its receptor to be upregulated in thyroid neoplasias. ${ }^{40}$ The causal link between PTTG and bFGF was established in FRTL5 (Fisher rat thyroid cell line 5) thyroid cells, in which overexpression of PTTG upregulated bFGF secretion. The most convincing data regarding the oncogenic potential of PTTG in thyroid cells were obtained by overexpressing PTTG in FRTL5 cells and in primary human thyroid cells in vitro, which resulted in transformation and produced a dedifferentiated, neoplastic phenotype. This observation was supported by a separate group reporting upregulation of PTTG and bFGF in differentiated thyroid cancers. ${ }^{41}$ In addition, expression of PTTG-binding protein mRNA was found to be higher in differentiated thyroid carcinomas than in normal thyroid and was independently associated with tumor recurrence. ${ }^{42}$ To summarize, the data suggest that PTTG, PTTG-binding protein, and bFGF are potential prognostic markers for thyroid malignancies, and the use of these markers may in the future guide the therapeutic regimen offered to the patients. However, the roles played by PTTG, PTTG-binding protein and bFGF in the genesis of thyroid cancer are uncertain at present.

\section{Colon cancer}

Colon cancer is one of the most common and most deadly forms of cancer in the western world. An investigation of PTTG expression in samples of colorectal polyps and tumors showed significant upregulation of PTTG mRNA in 68 consecutive unselected patients. ${ }^{43}$ Overexpression of PTTG also correlated with a higher tumor grade (stage $\mathrm{C}$ and $\mathrm{D}$ ) than the lower grade (stage A and B) carcinomas of the Duke classification. Furthermore, highly vascular colorectal carcinomas and adenomas express higher levels of PTTG mRNA than less-vascular samples. Finally, Heaney et al ${ }^{43}$ demonstrated that colorectal tumors with lymph node invasion had higher PTTG expression than carcinomas without lymph node invasion. Therefore, the detection of high PTTG expression in surgically excised colorectal tumor tissue 
Table 1. Current data on PTTG expression in various malignancies.

\begin{tabular}{|c|c|c|}
\hline & Cell-line/primary culture & Patient samples \\
\hline Pituitary cancer & $+{ }^{7 \dagger}$ & $+{ }^{17,18}$ \\
\hline Esophageal squamous cancer & & $+53,60$ \\
\hline Lung cancer & +47 & +62 \\
\hline Lymphoid cancer & +63 & $++^{64}$ \\
\hline Colon cancer & & +43 \\
\hline Breast cancer & & +66 \\
\hline Astrocytoma cancer & $+45,46$ & $+45,46$ \\
\hline
\end{tabular}

may be adjuvant information to the histology grade and useful for appropriate selection of post-surgical treatment. The mechanism behind the PTTG mRNA upregulation in malignant colonic tissue is currently unknown, but several factors are now known to regulate PTTG expression in a variety of cell systems. Overall, it is currently premature to state that disrupting PTTG actions could serve as a therapeutic approach for the treatment of colon cancer.

\section{Gliomas}

Astrocytomas are the most common and most deadly primary tumors found in the brain and carry a particularly poor prognosis, especially high-grade astrocytomas or gliomas. The activity and regulation of a number of mitogenic signaling pathways are aberrant in astrocytomas and are thought to play a crucial role in their development. The cascade of events leading to the formation and progression of astrocytomas from low- to high-grade is well characterized. ${ }^{44}$ Due to the emerging promalignant/oncogenic roles of PTTG, the positive correlation between PTTG expression and the degree of pituitary tumor invasiveness, and its high expression in most cancers including those of the thyroid and colon, we and others sought to study the expression pattern and regulation of PTTG in glioblastoma. ${ }^{45,46}$ These two studies demonstrated an upregulation of PTTG mRNA in astrocytomas as compared to normal astrocytes. In one study, the PTTG-binding protein was also found to be upregulated. In addition, knocking down PTTG expression by RNA silencing resulted in the inhibition of proliferation of an astrocytoma cell line. ${ }^{46}$ These studies again suggest that
PTTG is a very promising marker of malignancy. In the future, more conclusive studies will show whether PTTG is causative in the genesis of these malignancies, which would make PTTG a potential drug target.

Although, overexpression of PTTG has been implicated in the genesis and/or pathogenesis of various cancers, there is an exception. Overexpression of human PTTG in HeLa and A549 lung cancer cells inhibited cell growth and stimulated expression of the p21 gene, ${ }^{47}$ which is in contrast to the effects observed in pituitary adenomas. Therefore, PTTG overexpression may not always be associated with cancer cell growth, and we should be careful to determine the effect of its overexpression in other types of cancers in the future. In addition, how PTTG switches from normal physiologic function to behaving as an oncogene, as well as the importance of PTTG in the genesis of tumors other than pituitary adenoma, need to be determined.

In summary, there is a growing body of data demonstrating the utility of PTTG as a possible marker of thyroid carcinomas, colon adenocarcinoma, and gliomas, in addition to being a well-established marker of pituitary adenomas. Although PTTG was first discovered in pituitary adenomas, its importance in malignant transition appears to be more generalized than previously thought. PTTG expression in various cancer tissues is listed in table 1 , and its regulation is discussed below. 


\section{Regulation of PTTG Expression in Malignant Cells and Tissues}

Understanding aberrant activation of PTTG expression may provide insight into the function of the protein in various cancers. Characterization of the human PTTG promoter revealed that it consists of two transcription start sites, $37 \mathrm{bp}$ and $317 \mathrm{bp}$, upstream of the translational start site. ${ }^{48}$ The existence of these two sites suggests that the expression of PTTG is differentially regulated in tumor and normal tissues. The regulation of PTTG expression has been investigated in a number of malignant tissues. For example, PTTG is upregulated by estrogen and bFGF and downregulated by a peroxisome proliferator-activated receptor- $\gamma$ agonist, rosiglitazone, in pituitary adenomas. ${ }^{49,50}$ Astrocytic tumors, where PTTG expression positively correlates with the malignancy grades of astrocytomas, are upregulated by tumorigenic cytokines, such as epidermal growth factor, transforming growth factor- $\alpha$, hepatocyte growth factor and insulin-like growth factor-1.45,46 In H-500 Leydig cell tumors, a humoral hypercalcemia of malignancy model, PTTG is upregulated by extracellular $\mathrm{Ca}^{2+}$ acting via the calcium-sensing receptor. 51,52 Therefore, in pituitary adenomas, gliomas and Leydig cell tumors, PTTG expression shows a pattern of upregulation by tumor-promoting factors specific to these tumors. In human esophageal squamous cell carcinoma, overexpression of PTTG has been correlated with increased expression of the wnt signaling protein, $\beta$-catenin/ T-cell factor (TCF), which plays an important role in differentiation, morphogenesis and tumorigenesis. ${ }^{53,54}$ This report also showed that in human esophageal squamous carcinoma cells, the overexpression of PTTG probably results from possessing a putative TCF4-binding element in the PTTG gene. ${ }^{53}$ Interestingly, in both astrocytomas and MCF-7 breast tumor cells, upregulation of PTTG expression by insulin and insulin-like growth factor-1 involves a pro-survival PI3 kinase pathway, suggesting that mechanisms of tumor cell survival lead to overexpression of PTTG. At present, however, it remains unclear whether induction of PTTG by insulin and insulin-like growth factor-1 leads to tumorigenesis. The regulation of PTTG by various factors summarized in table 2 may help to understand the possible mediatory roles played by this protein in the genesis and/or progression of various cancers.

\section{PTTG and Tumor Suppressor Genes}

The p53 tumor suppressor gene is thought to be central in protecting against the development of cancer. The $\mathrm{p} 53$ protein functions as a transcription factor, regulating downstream genes involved in cell cycle arrest, DNA repair and programmed cell death. DNA damage is a potent stimulus for activation of p53 protein in repairing DNA damage and induces cellular apoptosis if the damage is too severe. Although available reports show an intimate relationship between PTTG and p53, its exact nature remains unclear. ${ }^{55-58}$ For example, PTTG overexpression, as occurs in many cancers, has been shown to induce cellular apoptosis by both p53-dependent and p53-independent mechanisms. The apoptotic effect is p53-dependent in MCF-7 breast cancer cells and p53-independent in MG-63 human osteosarcoma cells. In MCF-7 breast cancer cells, PTTG overexpression upregulates p53 expression and nuclear translocation with consequent apoptosis by activating a pro-apoptotic gene, bax. Upregulation of p53 by PTTG is indirect and is mediated through an oncogene, c-myc. These observations suggest that p53 is downstream of PTTG and that PTTG overexpression has a protective role against tumorigenesis by inducing cellular apoptosis.

Although overexpression of PTTG activates the p53 gene, PTTG itself is a downstream target of p53, suggesting an

Table 2. Regulation of PTTG expression by various growth factors and hormones.

\begin{tabular}{|c|c|c|}
\hline Growth factors/hormones & Cells & Effects on PTTG expression \\
\hline Estrogen & Pituitary adenoma50* & + \\
\hline bFGF & Pituitary adenoma 50 & + \\
\hline PPAR- $\gamma$ agonists & Pituitary adenoma49 & - \\
\hline $\mathrm{EGF/TGF} \alpha$ & Astrocytoma46 & + \\
\hline HGF & Astrocytoma46 & + \\
\hline Insulin, IGF-1 & Astrocytoma ${ }^{45}, \mathrm{MCF}-7$ breast cancer cells & + \\
\hline $\mathrm{Ca}^{2+}$ via the $\mathrm{CaR}$ & H-500 Leydig cell tumor52 & + \\
\hline \multicolumn{3}{|c|}{$\begin{array}{l}\text { * The numbers indicate references. } \\
+, \text { upregulation. -, downregulation. } \\
\text { bFGF, basic fibroblast growth factor; CaR, calcium-sensing receptor; EGF, epidermal growth factor; HGF, hepatocyte growth factor; IGF-1, } \\
\text { insulin-like growth factor-1; PPAR- } \gamma \text {, peroxisome proliferator-activated receptor-gamma; PTTG, pituitary tumor transforming gene; TGF, } \\
\text { transforming growth factor }\end{array}$} \\
\hline
\end{tabular}




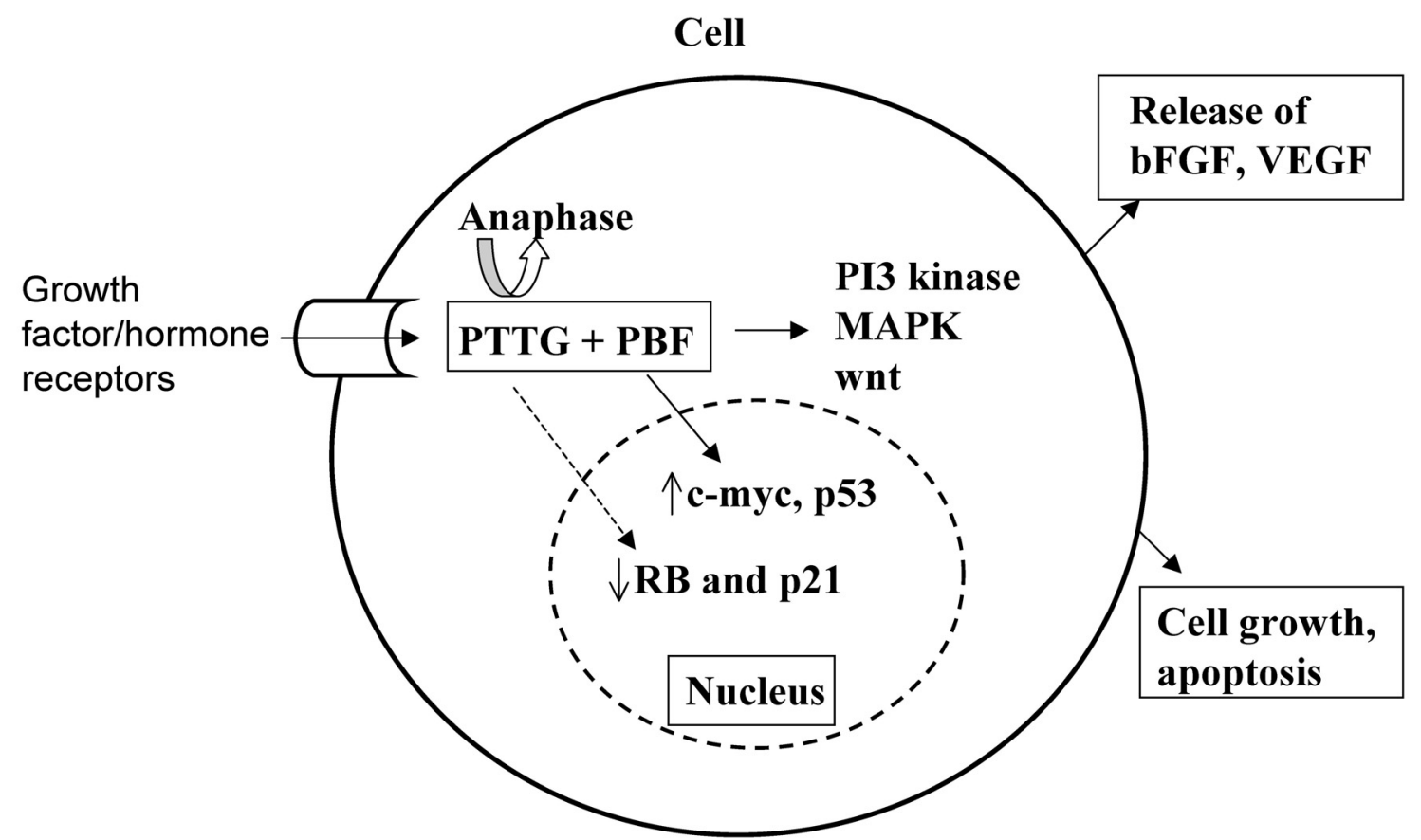

Figure 1. Schematic illustration of the regulation of PTTG expression, its activation and downstream signaling pathways in pituitary tumor cells. PTTG functions by activating MAP and PI kinase pathways, upregulating p53 and downregulating Rb and p21 expressions. Activation of PTTG has been shown to stimulate two pro-angiogeneic factors, VEGF and bFGF. Overall effect is increased cellular growth and angiogenesis.

important feedback mechanism between these two molecules. ${ }^{56}$ In a different study, ${ }^{58}$ induction of DNA damage by the chemotherapeutic drugs, doxorubicin and bleomycin, suppressed PTTG expression in the p53-expressing human colorectal cancer cell line, HCT111, and U2OS osteosarcoma cells, but not in p53-deficient cells, demonstrating that p53 is upstream of the PTTG gene and downregulates its expression in order to facilitate DNA repair.

Finally, another report demonstrated that overexpression of PTTG in human A549 lung cancer cells inhibits cellular growth through upregulation of $\mathrm{p} 21$, a cell cycle protein that is downstream of p53. ${ }^{47}$ However, no change in p53 mRNA was observed in A549 cells, indicating that PTTG regulates human lung cancer cell function by modulating the p21 pathway that bypasses the $\mathrm{p} 53$ protein. Heterogeneity in the regulation of cancer cell biology could only explain a varying relationship between PTTG and the tumor suppressor gene, p53. Whether disrupting the feedback relationship between PTTG and p53 could serve as a therapeutic strategy for cancer cells, needs to be investigated. A schematic illustration of how PTTG regulates cellular signaling and the resultant cellular response has been provided in figure 1 using a pituitary tumor cell as the model.

\section{Conclusion}

Since the cloning of PTTG in 1997 from pituitary tumor cells, our understanding of its structure, function and clinical importance has made impressive progress. A great body of data has enabled us to understand the molecular and cellular regulation of PTTG, and its biological functions. Increasing evidence regarding the roles of PTTG in various cancers, including pituitary adenoma, is making it a candidate marker of malignancy and a potential chemotherapeutic target. Data on PTTG mRNA expression in thyroid malignancies and colorectal cancer show high expression of PTTG in samples from patients with high-grade malignancies. Furthermore, the colorectal cancers that had lymph node invasion also had upregulation of PTTG, making PTTG upregulation a possible tool in the decision to use adjuvant therapy. In thyroid carcinomas, PTTG, PTTG-binding protein and bFGF are very promising prognostic markers for thyroid malignancies, and the use of these markers may, in the future, guide the therapeutic regimen offered to patients. In pituitary neoplasms and thyroid cancer, emerging evidence suggests that PTTG and its binding protein are involved in the malignant transformation of cells. Future studies will reveal whether PTTG is a drug target in these malignancies.

\section{Acknowledgments}

We sincerely thank the reviewers for their valuable suggestions and many insightful comments that have enormously helped to give final shape to this manuscript.

\section{References}

1. Zou H, McGarry TJ, Bernal T, Kirschner MW. Identification of a vertebrate sister-chromatid separation inhibitor involved in transformation and tumorigenesis. Science 1999;285:418-422.

2. Nasmyth K. Segregating sister genomes: the molecular biology of chromosome separation. Science 2002;297:559-565. 
3. Nasmyth K, Peters JM, Uhlmann F. Splitting the chromosome: cutting the ties that bind sister chromatids. Science 2000;288:1379-1385.

4. Peters JM. The anaphase-promoting complex: proteolysis in mitosis and beyond. Mol Cell 2002;9:931-943.

5. Yu H, Peters JM, King RW, Page AM, Hieter P, Kirschner MW. Identification of a cullin homology region in a subunit of the anaphase-promoting complex. Science 1998;279:1219-1222.

6. Harper JW, Burton JL, Solomon MJ. The anaphase-promoting complex: it's not just for mitosis any more. Genes Dev 2002; 16:2179-2206.

7. Pei L, Melmed S. Isolation and characterization of a pituitary tumor-transforming gene (PTTG). Mol Endocrinol 1997;11:433-441.

8. Zhang X, Horwitz GA, Prezant TR, Valentini A, Nakashima M, Bronstein MD, Melmed S. Structure, expression, and function of human pituitary tumor-transforming gene (PTTG). Mol Endocrinol 1999;13:156-166.

9. Horwitz GA, Miklovsky I, Heaney AP, Ren SG, Melmed S. Human pituitary tumor-transforming gene (PTTG1) motif suppresses prolactin expression. Mol Endocrinol 2003; 17:600-609.

10. McCabe CJ, Gittoes NJ. PTTG-a new pituitary tumour transforming gene. J Endocrinol 1999;162:163-166.

11. Chien W, Pei L. A novel binding factor facilitates nuclear translocation and transcriptional activation function of the pituitary tumor-transforming gene product. J Biol Chem 2000;275:19422-19427.

12. Boelaert K, Tannahill LA, Bulmer JN, Kachilele S, Chan SY, Kim D, Gittoes NJ, Franklyn JA, Kilby MD, McCabe CJ. A potential role for PTTG/securin in the developing human fetal brain. FASEB J 2003;17:1631-1639.

13. Wang Z, Moro E, Kovacs K, Yu R, Melmed S. Pituitary tumor transforming gene-null male mice exhibit impaired pancreatic beta cell proliferation and diabetes. Proc Natl Acad Sci U S A 2003;100:3428-3432.

14. Suhardja AS, Kovacs KT, Rutka JT. Molecular pathogenesis of pituitary adenomas: a review. Acta Neurochir (Wien) 1999; 141:729-736.

15. Yu R, Melmed S. Oncogene activation in pituitary tumors. Brain Pathol 2001;11:328-341.

16. McCabe CJ, Khaira JS, Boelaert K, Heaney AP, Tannahill LA, Hussain S, Mitchell R, Olliff J, Sheppard MC, Franklyn JA, Gittoes NJ. Expression of pituitary tumour transforming gene (PTTG) and fibroblast growth factor-2 (FGF-2) in human pituitary adenomas: relationships to clinical tumour behaviour. Clin Endocrinol (Oxf) 2003;58:141-150.

17. Saez C, Japon MA, Ramos-Morales F, Romero F, Segura DI, Tortolero M, Pintor-Toro JA. hpttg is over-expressed in pituitary adenomas and other primary epithelial neoplasias. Oncogene 1999;18:5473-5476.

18. Zhang X, Horwitz GA, Heaney AP, Nakashima M, Prezant TR, Bronstein MD, Melmed S. Pituitary tumor transforming gene (PTTG) expression in pituitary adenomas. J Clin Endocrinol Metab 1999;84:761-767.

19. Heaney AP, Horwitz GA, Wang Z, Singson R, Melmed S. Early involvement of estrogen-induced pituitary tumor transforming gene and fibroblast growth factor expression in prolactinoma pathogenesis. Nat Med 1999;5:1317-1321.

20. Atkin SL, Green VL, Hipkin LJ, Landolt AM, Foy PM, Jeffreys $\mathrm{RV}$, White MC. A comparison of proliferation indices in human anterior pituitary adenomas using formalin-fixed tissue and in vitro cell culture. J Neurosurg 1997;87:85-88.

21. Thapar K, Kovacs K, Scheithauer BW, Stefaneanu L, Horvath E, Pernicone PJ, Murray D, Laws ER Jr. Proliferative activity and invasiveness among pituitary adenomas and carcinomas: an analysis using the MIB-1 antibody. Neurosurgery 1996;38:99-106.
22. Knosp E, Kitz K, Perneczky A. Proliferation activity in pituitary adenomas: measurement by monoclonal antibody Ki-67. Neurosurgery 1989;25:927-930.

23. Thapar K, Scheithauer BW, Kovacs K, Pernicone PJ, Laws ER Jr. p53 expression in pituitary adenomas and carcinomas: correlation with invasiveness and tumor growth fractions. Neurosurgery 1996;38:765-770.

24. Abbud RA, Takumi I, Barker EM, Ren SG, Chen DY, Wawrowsky K, Melmed S. Early multipotential pituitary focal hyperplasia in the alpha-subunit of glycoprotein hormone-driven pituitary tumor-transforming gene transgenic mice. Mol Endocrinol 2005; 19:1383-1391.

25. Hu N, Gutsmann A, Herbert DC, Bradley A, Lee WH, Lee EY. Heterozygous Rb-1 delta 20/+mice are predisposed to tumors of the pituitary gland with a nearly complete penetrance. Oncogene 1994;9:1021-1027.

26. Classon M, Harlow E. The retinoblastoma tumour suppressor in development and cancer. Nat Rev Cancer 2002;2:910-917.

27. Chesnokova V, Kovacs K, Castro AV, Zonis S, Melmed S. Pituitary hypoplasia in Pttg-/- mice is protective for $\mathrm{Rb}+/$ pituitary tumorigenesis. Mol Endocrinol 2005;19:2371-2379.

28. Folkman J, Klagsbrun M. Angiogenic factors. Science 1987;235:442-447

29. Hanahan D, Folkman J. Patterns and emerging mechanisms of the angiogenic switch during tumorigenesis. Cell 1996;86:353-364.

30. Pei L. Identification of c-myc as a down-stream target for pituitary tumor-transforming gene. J Biol Chem 2001;276:8484-8491.

31. Zimering MB, Katsumata N, Sato Y, Brandi ML, Aurbach GD, Marx SJ, Friesen HG. Increased basic fibroblast growth factor in plasma from multiple endocrine neoplasia type 1: relation to pituitary tumor. J Clin Endocrinol Metab 1993;76:1182-1187.

32. Ray D, Melmed S. Pituitary cytokine and growth factor expression and action. Endocr Rev 1997;18:206-228.

33. Shimon I, Huttner A, Said J, Spirina OM, Melmed S. Heparin-binding secretory transforming gene (hst) facilitates rat lactotrope cell tumorigenesis and induces prolactin gene transcription. J Clin Invest 1996;97:187-195.

34. Gonsky R, Herman V, Melmed S, Fagin J. Transforming DNA sequences present in human prolactin-secreting pituitary tumors. Mol Endocrinol 1991;5:1687-1695.

35. McCabe CJ, Heaney AP. Pituitary tumour transforming gene in endocrine cancer. Clin Endocrinol (Oxf) 2003;58:673-682.

36. Hunter JA, Skelly RH, Aylwin SJ, Geddes JF, Evanson J, Besser GM, Monson JP, Burrin JM. The relationship between pituitary tumour transforming gene (PTTG) expression and in vitro hormone and vascular endothelial growth factor (VEGF) secretion from human pituitary adenomas. Eur J Endocrinol 2003;148:203-211.

37. Links TP, van Tol KM, Jager PL, Plukker JT, Piers DA, Boezen HM, Dullaart RP, de Vries EG, Sluiter WJ. Life expectancy in differentiated thyroid cancer: a novel approach to survival analysis. Endocr Relat Cancer 2005;12:273-280.

38. Utiger RD. Follow-up of patients with thyroid carcinoma. N Engl J Med 1997;337:928-930.

39. Heaney AP, Nelson V, Fernando M, Horwitz G. Transforming events in thyroid tumorigenesis and their association with follicular lesions. J Clin Endocrinol Metab 2001;86:5025-5032.

40. Shingu K, Fujimori M, Ito K, Hama Y, Kasuga Y, Kobayashi S, Itoh N, Amano J. Expression of fibroblast growth factor-2 and fibroblast growth factor receptor-1 in thyroid diseases: difference between neoplasms and hyperplastic lesions. Endocr J 1998;45:35-43. 
41. Boelaert K, McCabe CJ, Tannahill LA, Gittoes NJ, Holder RL, Watkinson JC, Bradwell AR, Sheppard MC, Franklyn JA. Pituitary tumor transforming gene and fibroblast growth factor-2 expression: potential prognostic indicators in differentiated thyroid cancer. J Clin Endocrinol Metab 2003;88:2341-2347.

42. Stratford AL, Boelaert K, Tannahill LA, Kim DS, Warfield A, Eggo MC, Gittoes NJ, Young LS, Franklyn JA, McCabe CJ. Pituitary tumor transforming gene binding factor: a novel transforming gene in thyroid tumorigenesis. J Clin Endocrinol Metab 2005;90:4341-4349.

43. Heaney AP, Singson R, McCabe CJ, Nelson V, Nakashima M, Melmed S. Expression of pituitary-tumour transforming gene in colorectal tumours. Lancet 2000;355:716-719.

44. Chattopadhyay N, Tfelt-Hansen J, Brown EM. PKC, p42/44 MAPK and p38 MAPK regulate hepatocyte growth factor secretion from human astrocytoma cells. Brain Res Mol Brain Res 2002;102:73-82.

45. Chamaon K, Kirches E, Kanakis D, Braeuninger S, Dietzmann $\mathrm{K}$, Mawrin C. Regulation of the pituitary tumor transforming gene by insulin-like-growth factor-I and insulin differs between malignant and non-neoplastic astrocytes. Biochem Biophys Res Commun 2005;331:86-92.

46. Tfelt-Hansen J, Yano S, Bandyopadhyay S, Carroll R, Brown EM, Chattopadhyay N. Expression of pituitary tumor transforming gene (PTTG) and its binding protein in human astrocytes and astrocytoma cells: function and regulation of PTTG in U87 astrocytoma cells. Endocrinology 2004;145:4222-4231.

47. Mu YM, Oba K, Yanase T, Ito T, Ashida K, Goto K, Morinaga H, Ikuyama S, Takayanagi R, Nawata H. Human pituitary tumor transforming gene (hPTTG) inhibits human lung cancer A549 cell growth through activation of p21(WAF1/CIP1). Endocr J 2003;50:771-781.

48. Kakar SS. Molecular cloning, genomic organization, and identification of the promoter for the human pituitary tumor transforming gene (PTTG). Gene 1999;240:317-324.

49. Heaney AP, Fernando M, Melmed S. PPAR-gamma receptor ligands: novel therapy for pituitary adenomas. J Clin Invest 2003;111:1381-1388.

50. Heaney AP, Fernando M, Melmed S. Functional role of estrogen in pituitary tumor pathogenesis. J Clin Invest 2002;109:277-283.

51. Tfelt-Hansen J, Brown EM. The calcium-sensing receptor in normal physiology and pathophysiology: a review. Crit Rev Clin Lab Sci 2005;42:35-70.

52. Tfelt-Hansen J, Schwarz P, Terwilliger EF, Brown EM, Chattopadhyay N. Calcium-sensing receptor induces messenger ribonucleic acid of human securin, pituitary tumor transforming gene, in rat testicular cancer. Endocrinology 2003;144:5188-5193.

53. Zhou C, Liu S, Zhou X, Xue L, Quan L, Lu N, Zhang G, Bai J, Wang Y, Liu Z, Zhan Q, Zhu H, Xu N. Overexpression of human pituitary tumor transforming gene (hPTTG), is regulated by beta-catenin /TCF pathway in human esophageal squamous cell carcinoma. Int J Cancer 2005;113:891-898.

54. Peifer M, Polakis P. Wnt signaling in oncogenesis and embryogenesis - a look outside the nucleus. Science 2000;287:1606-1609.

55. Bernal JA, Luna R, Espina A, Lazaro I, Ramos-Morales F, Romero F, Arias C, Silva A, Tortolero M, Pintor-Toro JA. Human securin interacts with p53 and modulates p53-mediated transcriptional activity and apoptosis. Nat Genet 2002;32:306-311.

56. Hamid T, Kakar SS. PTTG/securin activates expression of p53 and modulates its function. Mol Cancer 2004;3:18.
57. Yu R, Heaney AP, Lu W, Chen J, Melmed S. Pituitary tumor transforming gene causes aneuploidy and p53-dependent and p53-independent apoptosis. J Biol Chem 2000;275:36502-36505.

58. Zhou Y, Mehta KR, Choi AP, Scolavino S, Zhang X. DNA damage-induced inhibition of securin expression is mediated by p53. J Biol Chem 2003;278:462-470.

59. Kim D, Pemberton H, Stratford AL, Buelaert K, Watkinson JC, Lopes V, Franklyn JA, McCabe CJ. Pituitary tumour transforming gene (PTTG) induces genetic instability in thyroid cells. Oncogene 2005;24:4861-4866.

60. Shibata Y, Haruki N, Kuwabara Y, Nishiwaki T, Kato J, Shinoda N, Sato A, Kimura M, Koyama H, Toyama T, Ishiguro H, Kudo J, Terashita Y, Konishi S, Fujii Y. Expression of PTTG (pituitary tumor transforming gene) in esophageal cancer. Jpn J Clin Oncol 2002;32:233-237.

61. Tsai SJ, Lin SJ, Cheng YM, Chen HM, Wing LY. Expression and functional analysis of pituitary tumor transforming gene-1 [corrected] in uterine leiomyomas. J Clin Endocrinol Metab 2005;90:3715-3723.

62. Honda S, Hayashi M, Kobayashi Y, Ishikawa Y, Nakagawa K, Tsuchiya E. A role for the pituitary tumor-transforming gene in the genesis and progression of non-small cell lung carcinomas. Anticancer Res 2003;23:3775-3782.

63. Dominguez A, Ramos-Morales F, Romero F, Rios RM, Dreyfus F, Tortolero M, Pintor-Toro JA. hpttg, a human homologue of rat pttg, is overexpressed in hematopoietic neoplasms. Evidence for a transcriptional activation function of hPTTG. Oncogene 1998;17:2187-2193.

64. Saez C, Pereda T, Borrero JJ, Espina A, Romero F, Tortolero M, Pintor-Toro JA, Segura DI, Japon MA. Expression of hpttg proto-oncogene in lymphoid neoplasias. Oncogene 2002;21:8173-8177.

65. Wen CY, Nakayama T, Wang AP, Nakashima M, Ding YT, Ito M, Ishibashi H, Matsuu M, Shichijo K, Sekine I. Expression of pituitary tumor transforming gene in human gastric carcinoma. World J Gastroenterol 2004;10:481-483.

66. Solbach C, Roller M, Fellbaum C, Nicoletti M, Kaufmann M. PTTG mRNA expression in primary breast cancer: a prognostic marker for lymph node invasion and tumor recurrence. Breast 2004;13:80-81.

\section{Author Affiliations}

Jacob Tfelt-Hansen, MD, Division of Endocrinology, Diabetes and Hypertension, Department of Medicine and Membrane Biology Program, Harvard Medical School, Boston, Massachusetts 02115; and Laboratory of Molecular Cardiology, Department of Cardiology, Copenhagen University Hospital Rigshospitalet, 20 Juliane Maries Vej, Section 9312, DK 2100 Copenhagen O, Denmark

Deepthi Kanuparthi, MSc, Division of Endocrinology, Diabetes and Hypertension, Department of Medicine and Membrane Biology Program, Harvard Medical School, Boston, Massachusetts 02115

Naibedya Chattopadhyay, PhD, Division of Endocrinology, Diabetes and Hypertension, Department of Medicine and Membrane Biology Program, Harvard Medical School, Boston, Massachusetts 02115 